\title{
Artigo \\ Aplicação de tecnologias de Automação industrial para melhoria de processos de produção: Um estudo de caso
}

\author{
Elton da Silva Freitas ${ }^{[1]}$, Matheus Emanuel Tavares Sousa ${ }^{[2]}$, Herick Talles Queiroz Lemos ${ }^{[3]}$, \\ Humberto Dionísio de Andrade ${ }^{[4]}$, José Lucas da Silva Paiva ${ }^{[5]}$ \\ ${ }^{[1]}$ Instituto Federal Rio Grande do Norte; eltonfreitas.g@ hotmail.com \\ [2] Universidade Federal Rural do Semi-Árido; matheus.sousa@ufersa.edu.br \\ ${ }^{[3]}$ Universidade Federal Rural do Semi-Árido; herick.lemos@ufersa.edu.br \\ [4] Universidade Federal Rural do Semi-Árido; humbertodionisio@ufersa.edu.br \\ ${ }^{[5]}$ Universidade Federal Rural do Semi-Árido; jose.paiva@ufersa.edu.br
}

Recebido: 06/07/2020;

Aceito: 09/08/2020;

Publicado: 11/09/2020.

Resumo: Este artigo apresenta a aplicação de técnicas de programação através de softwares intrínsecos a hardwares industriais para a operação e funcionamento de máquinas industriais de forma que acarretem melhorias com relação a lucratividade nos processos de produção, justificando-se desta forma a relevância desse tema para a formação do profissional de engenharia das diversas áreas. Na prática realizada, as funções requeridas foram executadas utilizando-se dois softwares. Primeiramente, foi implementado a função na interface homem-máquina (IHM) utilizando-se suas ferramentas de design para seguir o padrão existente do fabricante da máquina Empacotadora, e também ferramentas de funções de programa para interface com o Controlador lógico programável (CLP); e, na segunda etapa do trabalho, foi feito a lógica de acionamento da função de controle foi programada no CLP usando a linguagem ladder. Com a aplicação apresentada por este trabalho, foram obtidos resultados satisfatórios, que incluem o incremento de $35 \%$ na produtividade por linha de produção, e a valorização em torno de $47 \%$ do produto principal da indústria.

Palavras-chave: Técnicas de programação, Interface Homem Máquina, software e linhas de produção.

Abstract: This paper presents the application of programming techniques with software intrinsic to industrial hardware for the operation and working of industrial machines so that lead to improvements in terms of profitability in production processes, thus justifying the relevance of this theme for training engineering professional from different areas. In practice, the required functions were performed using two softwares. First, the function was implemented in the human-machine interface (HMI) using its design tools to follow the existing standard of the packaging machine manufacturer, as well as program function tools to interface with the programmable logic controller (PLC); and, in the second stage of the work, the logic for activating the control function was programmed in the PLC using the ladder language. With the application presented in this work, satisfactory results were obtained, which include a $35 \%$ increase in productivity per production line, and an appreciation about $47 \%$ of the main product of the industry.

Key-words: Programming techniques, Human Machine Interface, software and production lines.

\section{INTRODUÇÃO}

$\mathrm{N}$ as grandes indústrias os volumes de produção para atender a sociedade apresentaram crescimento médio de $1,66 \%$ nos últimos cinco anos, ressaltando o maior percentual de $4,5 \%$ durante o ano de 2017 , e neste contexto a administração do tempo de produção é essencial, trazendo consigo exigências no quesito confiabilidade e excelência em linhas e processos de produção [1]. 
A automação industrial possui um papel importante nesta temática, pois trata da operação e acionamento de máquinas e de processos nas indústrias. Dessa forma, os tempos e os movimentos que o trabalhador utiliza na execução de uma tarefa podem ser estudados e otimizados de acordo com leis científicas, possibilitando elevar assim o rendimento do trabalho a níveis nunca alcançados [2].

A necessidade de níveis de produção cada vez mais elevados, com maior qualidade e confiabilidade, resultaram na revolução industrial ocorrida no século XVIII [3]. A revolução trouxe consigo uma grande mudança na indústria com o aumento da produtividade, do lucro, da exigência de qualidade, dentre muitas outras. Neste cenário, as indústrias viram-se obrigadas a investir em novas tecnologias para suprir a grande demanda do mercado [4].

No contexto atual, nota-se que o aumento da competividade tem feito com que as empresas busquem, constantemente, a melhoria de seus processos, uma vez que o aperfeiçoamento dos mesmos pode trazer aumento da produtividade, bem como redução dos custos de produção [5]. Sendo assim, o principal motor da automação é a busca de maior qualidade dos processos, para reduzir perdas (com reflexo em custos) e possibilitar a fabricação de bens que de outra forma não poderiam ser produzidos, bem como do aumento da sua flexibilidade [6].

Neste artigo é apresentada uma implementação por meio de software no processo de controle de alimentação do produto acabado em duas linhas de produção, sugerida pela gestão de uma indústria alimentícia na cidade de Mossoró-RN, com objetivo de aprimorar o processo de produção com relação à administração do fator tempo nessa etapa de produção.

\section{MATERIAIS E MÉTODOS}

Nesta seção serão apresentadas as atividades metodológicas propostas para a execução da atividade.

\subsection{Descrição da problemática}

Nesta sub-seção será abordado o cenário de planejamento e distribuição temporal de tarefas e procedimentos operacionais padrões executados pela operação e definidos como roteiros pela Gestão de operação e produção da empresa, como também explanará a composição detalhada das linhas de produção que receberam a aplicação das técnicas abordadas por este trabalho.

A indústria possui três turnos, A, B e C assim denominados, de expediente de trabalho. Todos os turnos possuem uma pausa de uma hora para refeições e descanso durante a semana de segunda-feira a sábado. Antes de iniciar todos os turnos, é feito o primeiro procedimento padrão inicial de limpeza e ajustes nas máquinas com duração de 20 minutos, e também ao final de cada turno com mesma duração. Também no início do turno e no retorno da pausa para refeição e descanso, é realizado o procedimento operacional de limpeza da balança (cabeçote dosador) com drenagem do produto e ajuste zero- Estima-se que o tempo que o operador leva para desligar a chave geral da balança, religá-la novamente e aguardar a inicialização do equipamento seja de aproximadamente 40 segundos, somados a este tempo mais 60 segundos que são gastos enquanto o equipamento descarrega todo o produto e realiza o ajuste zero, totalizando 100 segundos, dobrando para 200 segundos considerando as duas vezes que este procedimento é realizado em um turno.

A velocidade de produção da máquina empacotadora é de 60 pacotes por minuto, ou seja, um pacote por segundo.A indústria fabrica diversos produtos. Sabe-se que o valor do produto principal com maior valor de mercado comercializado pela indústria, que é um pacote embalado com $500 \mathrm{~g}$ é de $\mathrm{R} \$ 0,80$. A quantidade de 200 pacotes que são deixados de serem produzidos devido a procedimentos operacionais de rotina gera um valor anual que é perdido pela empresa e estimado em torno de R \$138.240,00. Se o procedimento operacional de limpeza de balança é deixado de ser executado, a máquina não é capaz de fechar o pacote devido à alta quantidade de produto ocasionado pela vibração que enche as canecas de pesagem, e então o produto é desperdiçado e desta forma é reaproveitado em outro produto (ração animal), porém com valor estimado por quilo em $\mathrm{R} \$ 0,85$, e assim representa uma desvalorização de quase $50 \%$ se comparado ao produto principal, sem mencionar a embalagem que também é desperdiçada.

A linha de produção é composta por três máquinas. A primeira trata-se de uma balança de múltiplos cabeçotes (Cabeçote dosador) com 14 canecas de pesagem do fabricante Japonês, Ishida, modelo CCW-SE214, como mostra a Figura 1. O produto desce do silo de armazenagem por gravidade e alimenta uma esteira, que transporta o produto até o prato de dispersão da balança, sendo que o controle da quantidade de produto que desce intermitentemente é feito apenas por um valor " $X$ " de peso sobre o prato de dispersão, determinado no programa na Interface Homem-Máquina (IHM) de controle da balança. 


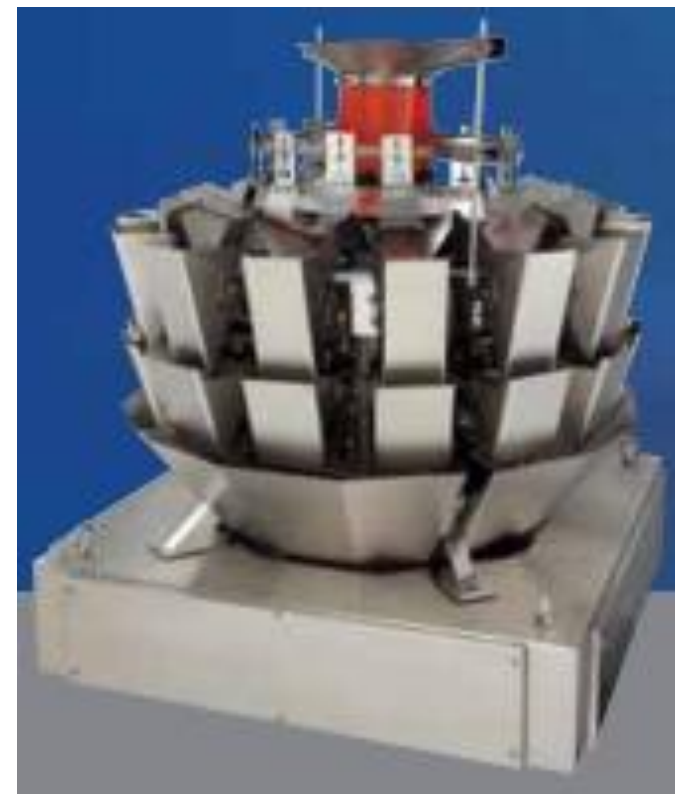

FIGURA 1. E Balança de múltiplos cabeçotes Ishida, CCW-SE-214.

A segunda máquina é uma Empacotadora automática vertical, do fabricante Raumak Packaging, modelo Speed Bag R7, como mostra a Figura 2, que recebe o produto dosado em 500g pela balança (Cabeçote dosador) e tem uma performance de produção de 60 pacotes por minuto.

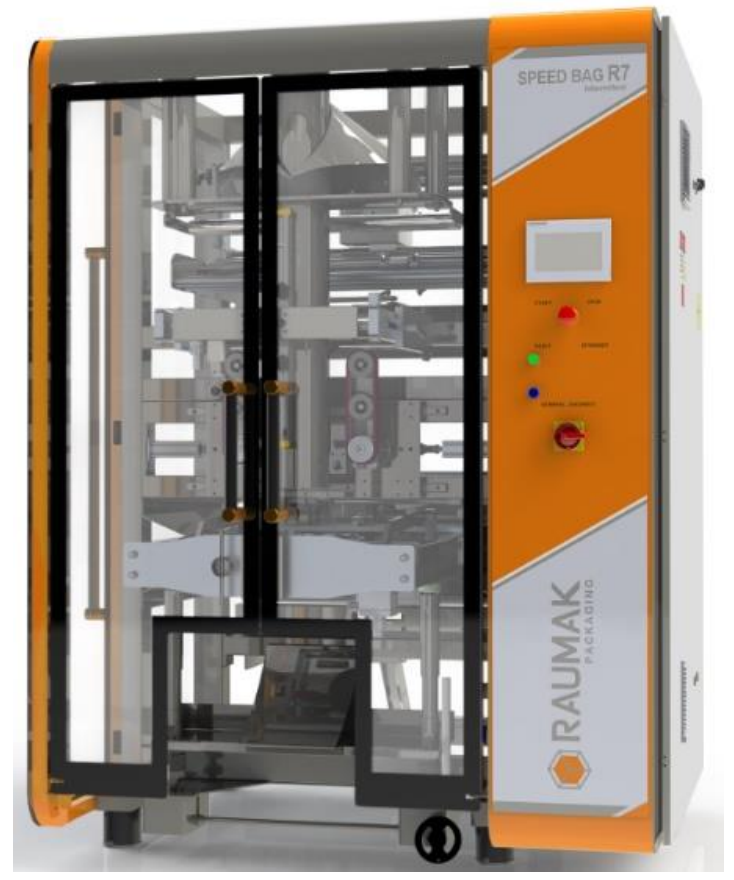

FIGURA 2. Empacotadora Raumak Packaging vertical Speed Bag R7.

A terceira máquina é uma enfardadora do fabricante Indumak Indústria de Máquinas Kreis Ltda, modelo MK 30, como apresenta a Figura 3, que recebe os pacotes produzidos pela empacotadora e produz embalagens tipo fardo com 30 pacotes cada, e em seguida os entrega a uma esteira posterior que direciona para armazenagem no galpão. 


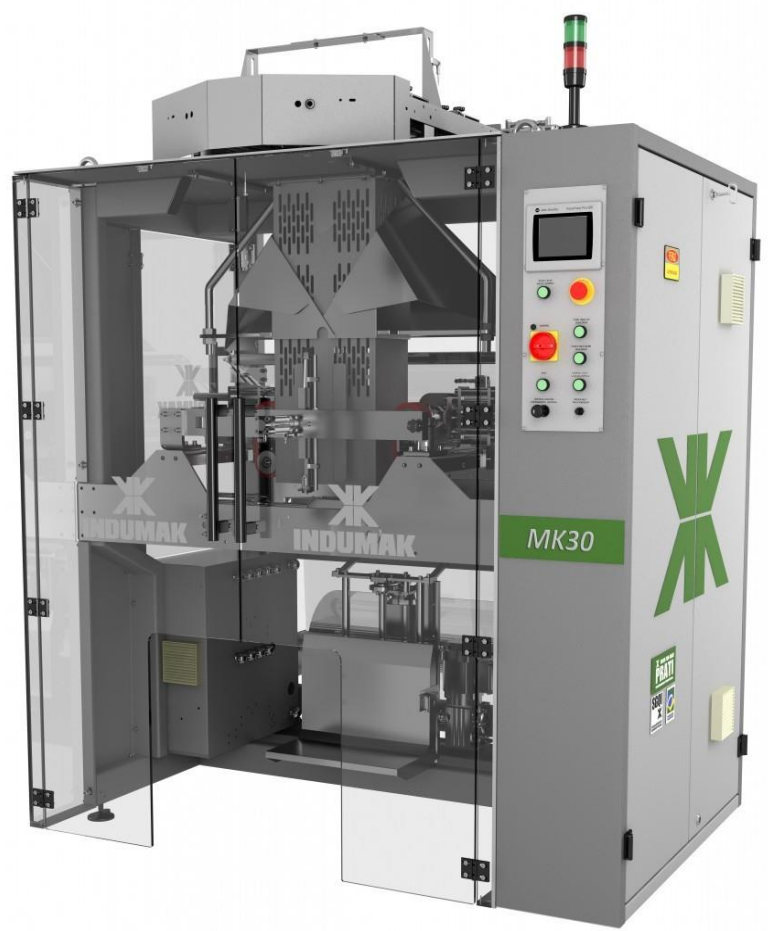

FIGURA 3. Enfardadora Indumak MK 30.

Na Figura 4 é ilustrado o processo da linha de produção. As setas amarelas e com a letra "P" indicam o produto acabado para envase.

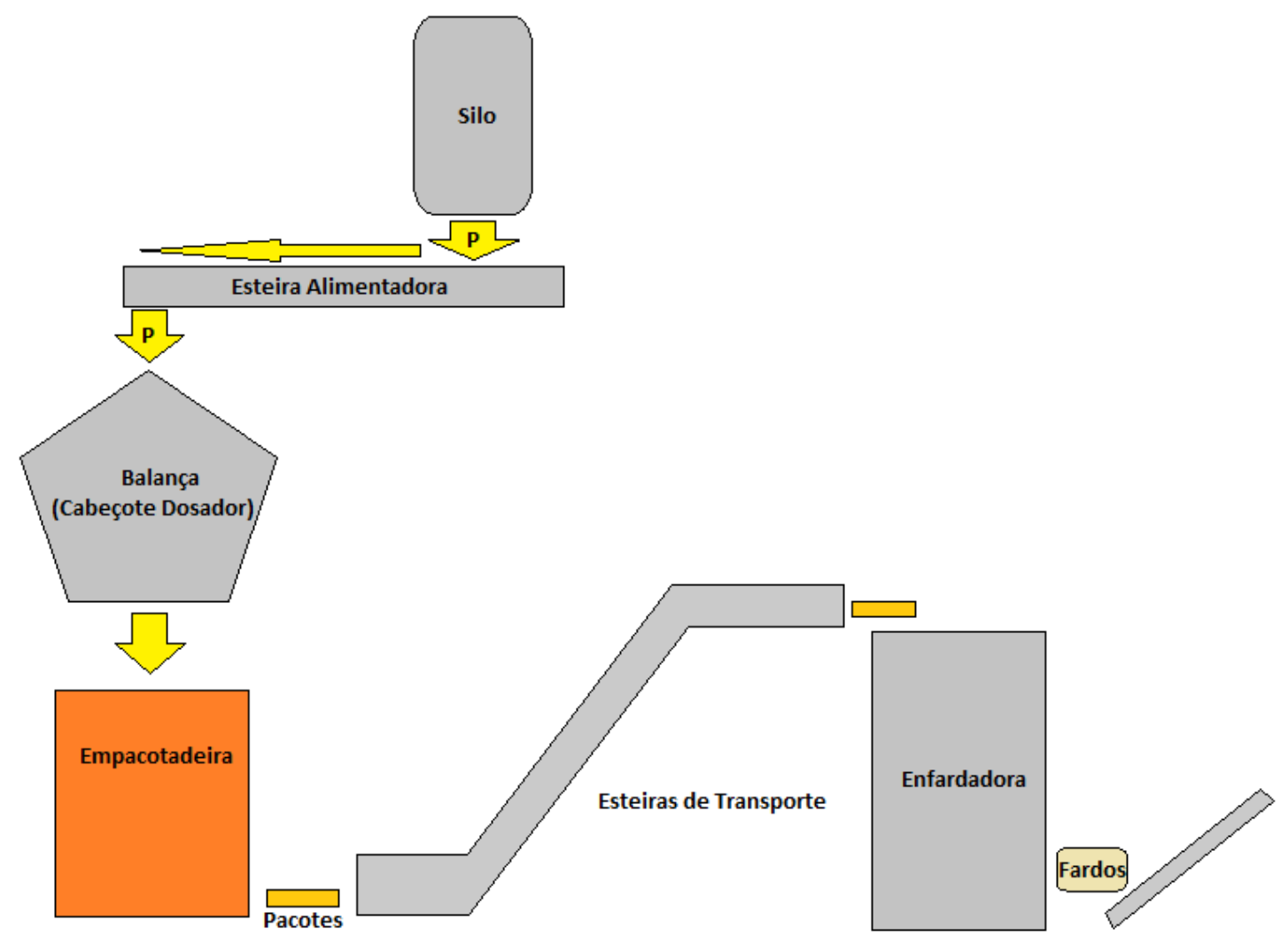

FIGURA 4. Ilustração de processo da linha de produção.

A estrutura que comporta a balança (Cabeçote dosador) recebe vibração estrutural devido a existência de grandes máquinas do processo primário da matéria prima. Esta vibração, faz com que preencha as 
canecas da balança, e quando se inicia a produção, há influência na pesagem ideal do produto, trazendo grandes prejuízos como desperdício de embalagens e produto acabado. O fluxograma ilustrado na Figura 5 apresenta o ciclo de produção da indústria, desde a fase inicial da matéria prima até o produto acabado.

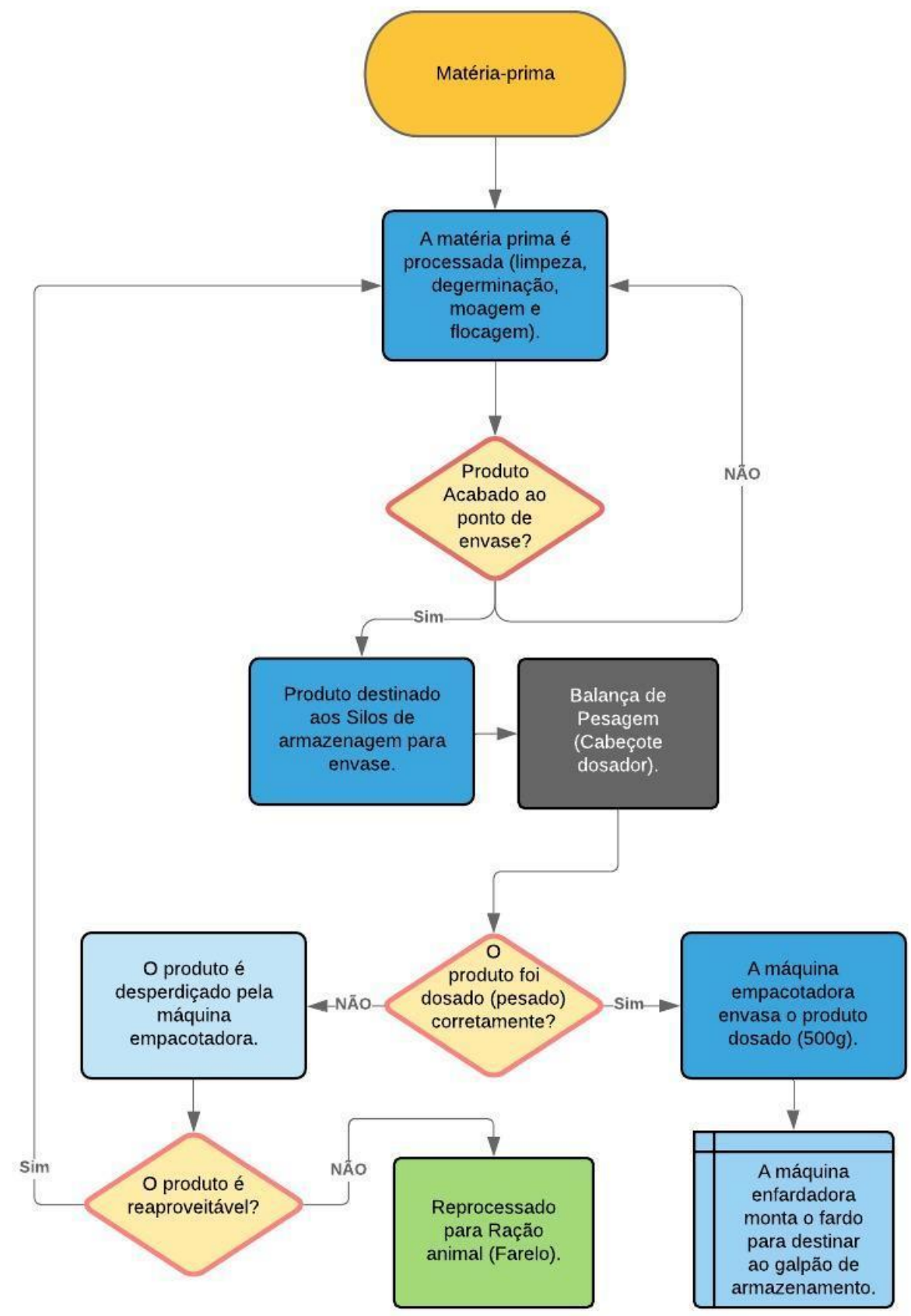

Figura 5. Fluxograma do Processo Fabril completo.

Para evitar danos onerosos como desperdício do produto primário principal, é necessário antes de colocar a linha para produzir realizar um esvaziamento/ajuste zero da balança para garantir que as canecas realizem a correta pesagem e descarga do produto. Neste procedimento operacional a máquina esvazia as canecas para realizar a pesagem correta. Porém o controle do alimentador não permite esse esvaziamento das canecas, pois sempre que se inicia o esvaziamento a esteira alimentadora tende a completar a quantidade de produto acabado até o "X" valor de controle do peso do prato de dispersão. Para contornar, o operador sempre desperdiça muito tempo para desligar a chave geral da balança, religá-la novamente, aguardar a reinicialização da balança dosadora e então assim, realizar o esvaziamento sem que o alimentador interfira no procedimento operacional. 


\subsection{Implementação da função de controle de produção do alimentador}

A função em estudo neste trabalho foi implementada através dos softwares Connected Components Workbench $^{\mathrm{TM}}(\mathrm{CCW})$, onde foi desenvolvido e incrementado o dispositivo de controle de acionamento na IHM do Alimentador da balança de pesagem (cabeçote dosador), tanto no quesito design quanto no quesito programação; o RSLinx Classic ${ }^{\mathrm{TM}}$, responsável por possibilitar a comunicação entre plataforma de programação, um notebook, IHM e o CLP; e o RSLogix 500® onde foi realizada a implementação no programa da máquina empacotadora no CLP. A IHM se encontrava com uma versão de firmware acima da permitida e aceitável pela versão do CCW. Para solução deste problema foi atualizado a versão v8 do software para a versão v11, capaz de atender e permitir a comunicação.

\subsubsection{Desenvolvimento da função de controle na IHM através do CCW}

A primeira etapa da prática foi feita a partir do uso do software Connected Components Workbench ${ }^{\mathrm{TM}}$ conjuntamente com o RSLinx Classic $^{\mathrm{TM}}[7,8,9]$.

\subsubsection{Manipulação e elaboração da comunicação através do RSLinx Classic $^{\mathrm{TM}}$}

A princípio, foi utilizado um notebook da própria indústria que comportava todos os softwares necessários. A primeira ação foi conectar fisicamente o cabo de rede Ethernet na entrada de rede da máquina empacotadora, que leva a conexão ao Switch numa topologia linear, diferentemente da topologia anel, onde estão conectados na rede a IHM e o CLP da máquina. Feito isto, foi acessado o RSLinx Classic ${ }^{\mathrm{TM}}$ no computador para autenticar a comunicação com a IHM. Na aba Communications, foi selecionado a tela de configurar drivers como mostra a Figura 6 a sequência de telas, onde é possível configurar diversos tipos de protocolos de comunicações (DF1, DH485, DeviceNET, entre outros), a depender do tipo de cabo utilizado para a comunicação, como por exemplo o tipo DF1 que se faz quando se usa o cabo serial RS232. Neste caso, foi selecionado o tipo EtherNet/IP Driver, e em seguida na caixa de diálogo Add New RSLinx Driver foi nomeado o driver sugerido pela Rockwell como AB_ETHIP-1. Em seguida para finalizar, a tela de configurar drivers: AB_ETHIP-1 ressurgiu, para selecionar a opção de rede local Subnet no modo Windows default, configurado para permitir a comunicação. A Rockwell Automation recomenda um IP padrão para a estação de trabalho que deseja interagir com os equipamentos, e com ciência deste requisito, foi alterado o IP do notebook para 192.168.1.10. Desta forma foi finalizado a autenticação da comunicação entre estação de trabalho e equipamentos, IHM e CLP.

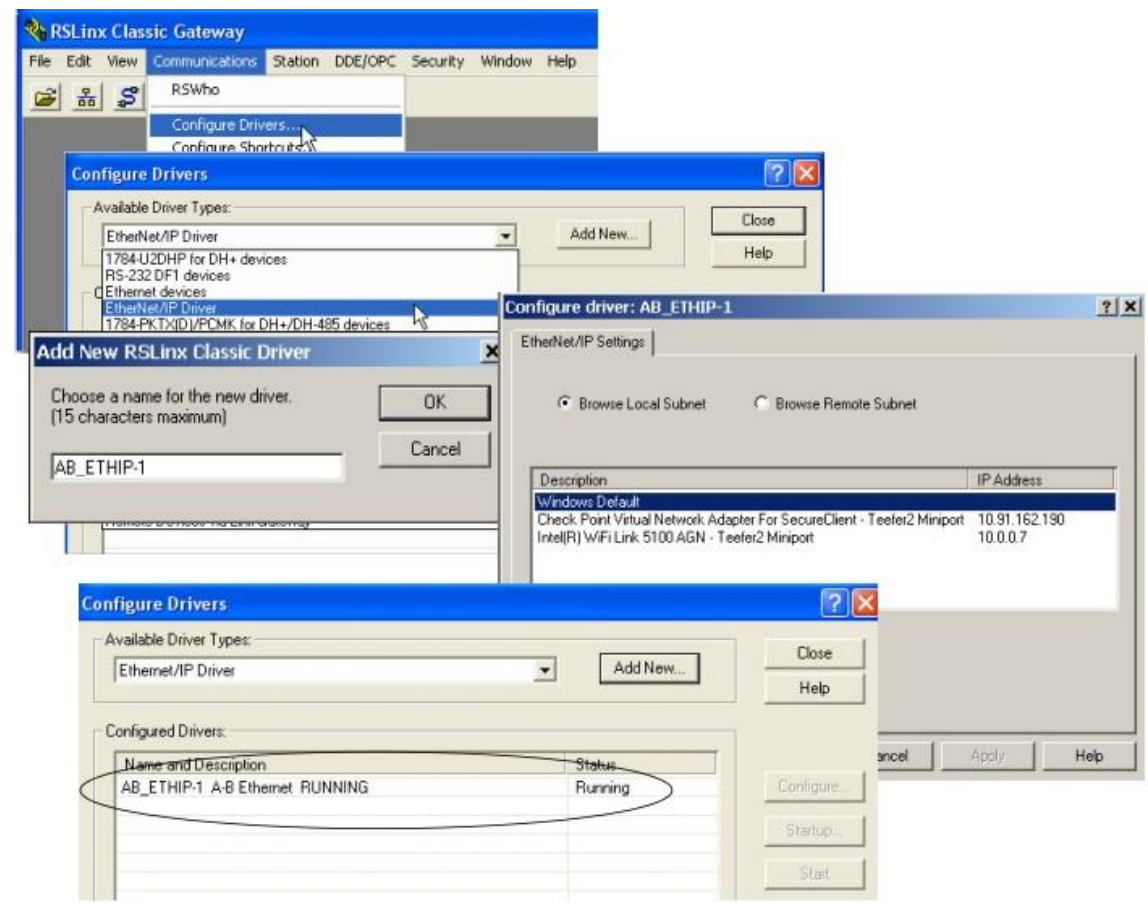

FIGURA 6. Sequência de telas de procedimento de comunicação através do RSLinx Classic $^{\mathrm{TM}}$, da Rockwell Automation. 


\subsubsection{Incremento da função no Programa da IHM}

Após a configuração do driver e comunicação bem-sucedida efetuada pelo RSLinx Classic ${ }^{\mathrm{TM}}$, foi inicializado o Connected Components Workbench ${ }^{\mathrm{TM}}(\mathrm{CCW})$ para que pudesse ser realizado o upload do programa de operação da máquina empacotadora, desenvolvido pelo próprio fabricante, contido na IHM, para o desenvolvimento da função incrementada. Como esta ação se tratava de um incremento em um programa já existente, na tela inicial do CCW foi selecionado a opção Discover, termo do software que é usado para carregar pela primeira vez um programa de um controlador já existente. Na sequência foi localizado e selecionado o controlador Micro800®, a IHM, na janela Connection Browser, e em seguida OK. Nota-se como mostra a Figura 7, o nome definido anteriormente do driver configurado AB_ETHIP-1, pela rede Ethernet.

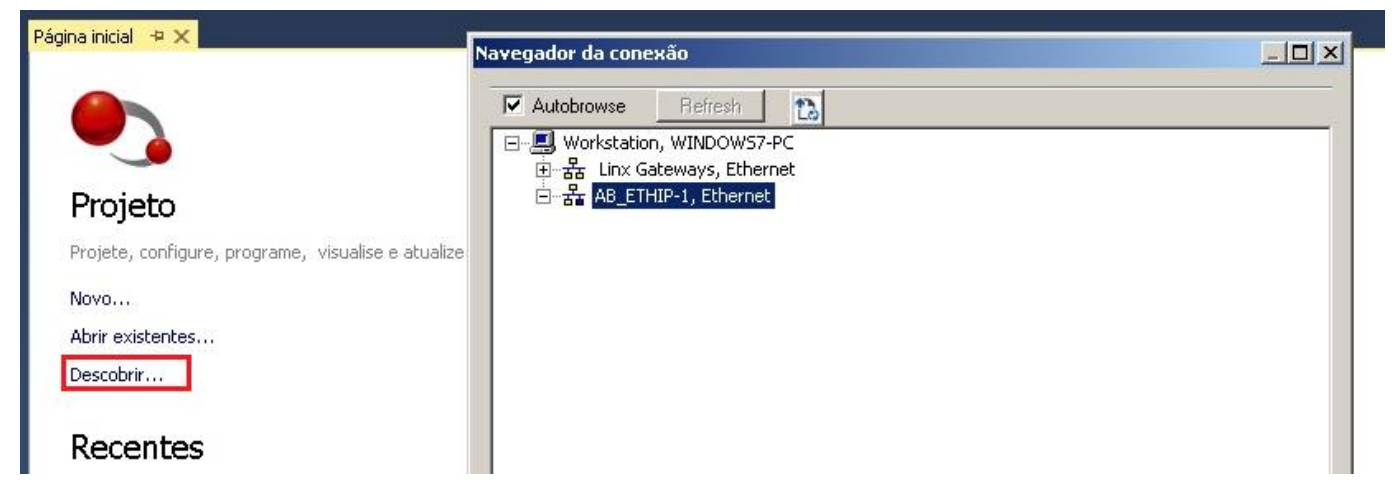

FIGURA 7. Tela inicial do software Connected Components Workbench ${ }^{\mathrm{TM}}$.

Tomado ciência disto, foi navegado até a tela de habilitações de funções da máquina, em seguida, tendo em vista que já existiam diversos botões de funções, e o botão que seria criado tinha o mesmo propósito de controlar a habilitação de uma nova função, então foi selecionado a opção de inserção de um botão do tipo pulsador mantido, como um dos botões já existentes, em seguida replicado as configurações gráficas, e posteriormente posicionado no espaço existente reservado. Essa sequência de ações é mostrada na Figura 8.

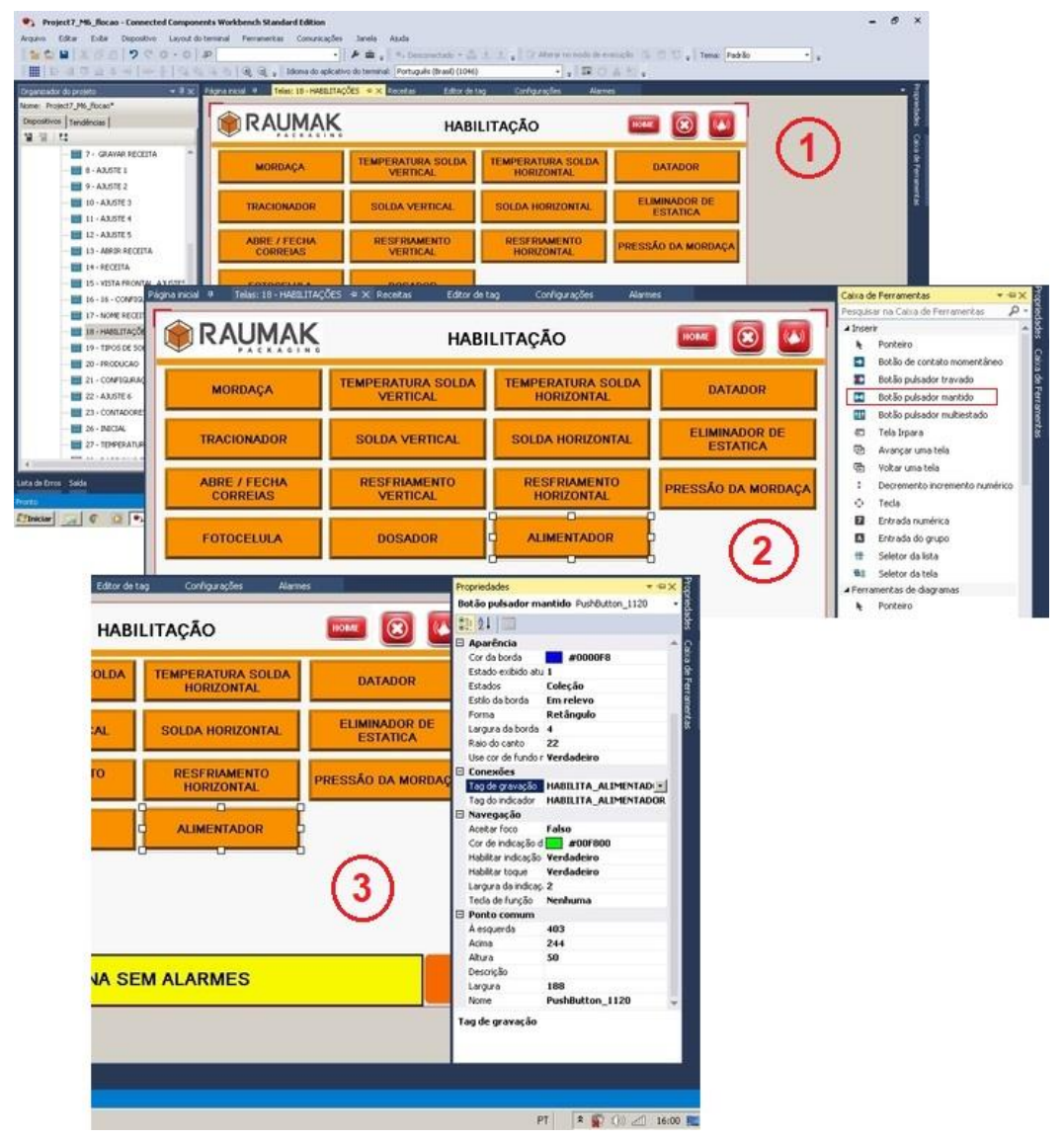


FiguRA 8. Sequência de Telas CCW. Fonte: Autoria Própria, 2019.

Após a elaboração do botão funcional, foi definido na tela de tag's a atribuição do endereço binário para utilização da função efetivamente no programa do CLP da máquina. O endereço foi definido como B3:14/14, com tipo de dados Boolean por se tratar apenas de mudança de estados em 0 ou 1, como mostra a Figura 9.

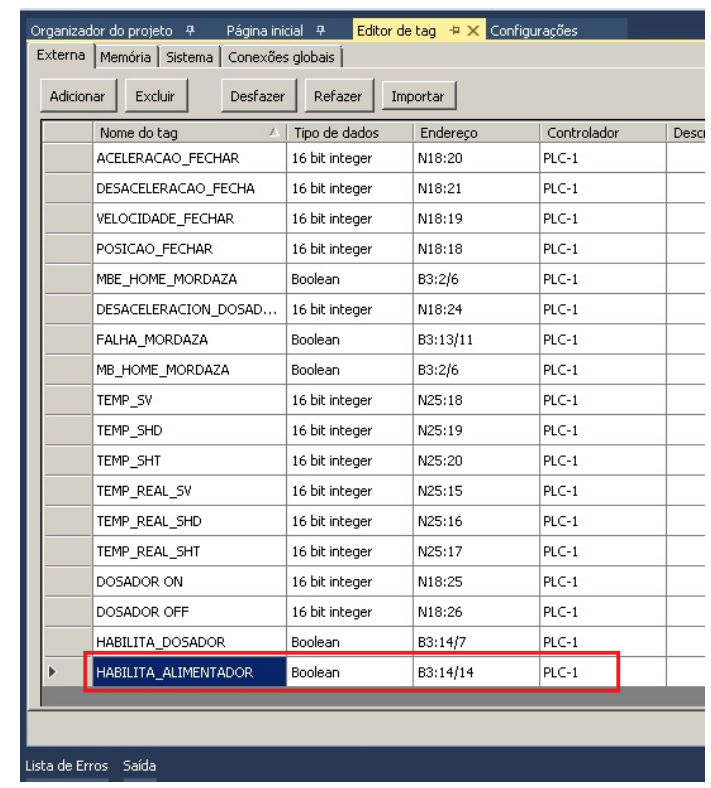

FIGURA 9. Tela de TAG's

Em seguida, foi inicializada a etapa de download do programa para a IHM após as modificações. Na aba de configurações, foi selecionado a opção Baixar, após selecionado o protocolo de comunicação condizente, Ethernet | Allen Bradley MicroLogix/ENI. Feito isto, o soft realiza uma varredura de validação do programa com o objetivo de encontrar alguma inconsistência. Caso não encontre anomalias, o programa é validado e a caixa de comunicação é mostrada para seleção do hardware onde se deseja descarregar o programa. Este passo a passo é mostrado na Figura 10. Com isto foi finalizado esta etapa do trabalho.

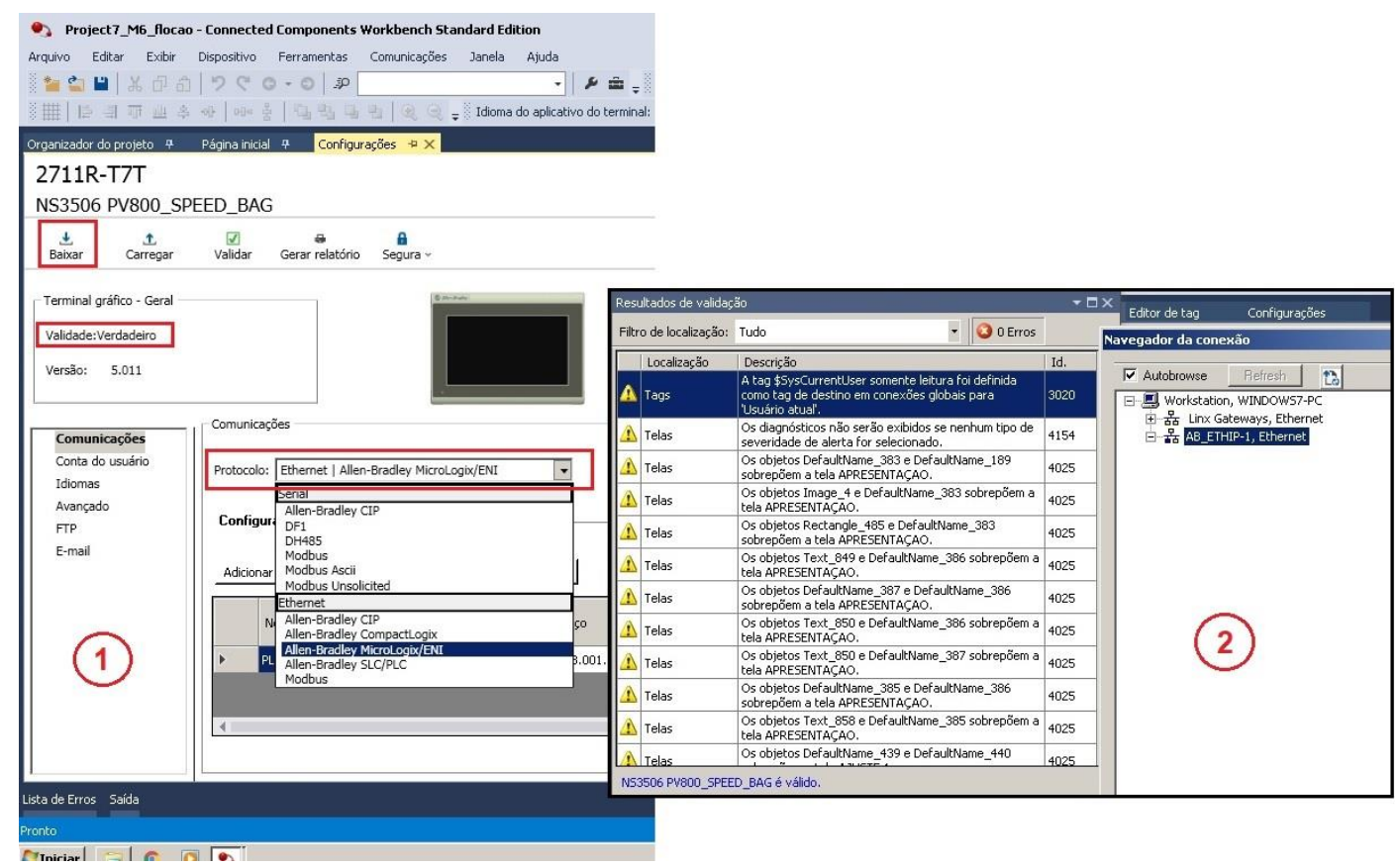

FIGURA 10. Descarregando programa e validação 
2.2.1.3. Desenvolvimento do incremento da linha de programa no CLP

Nesta etapa, primeiramente foi iniciado o soft RSLogix 500® e em seguida prosseguido com o processo de comunicação entre computador e CLP. Na aba Comms como mostra a Figura 11, foi acessado a opção System Comms, que exibiu uma nova janela denominada Communications, onde foi possível selecionar o driver configurado através do RSLinx Classic ${ }^{\mathrm{TM}}$, anteriormente, e assim definir o protocolo de comunicação. Após este processo, foi realizado o upload do programa do CLP da máquina através da caixa de status do RSLogix $500 \AA$, como é possível visualizar ainda na Figura 10. Com isto, o soft passou a exibir a programação de funcionamento da máquina empacotadora na linguagem Ladder, que é a padrão do RSLogix 500® [10, 11].

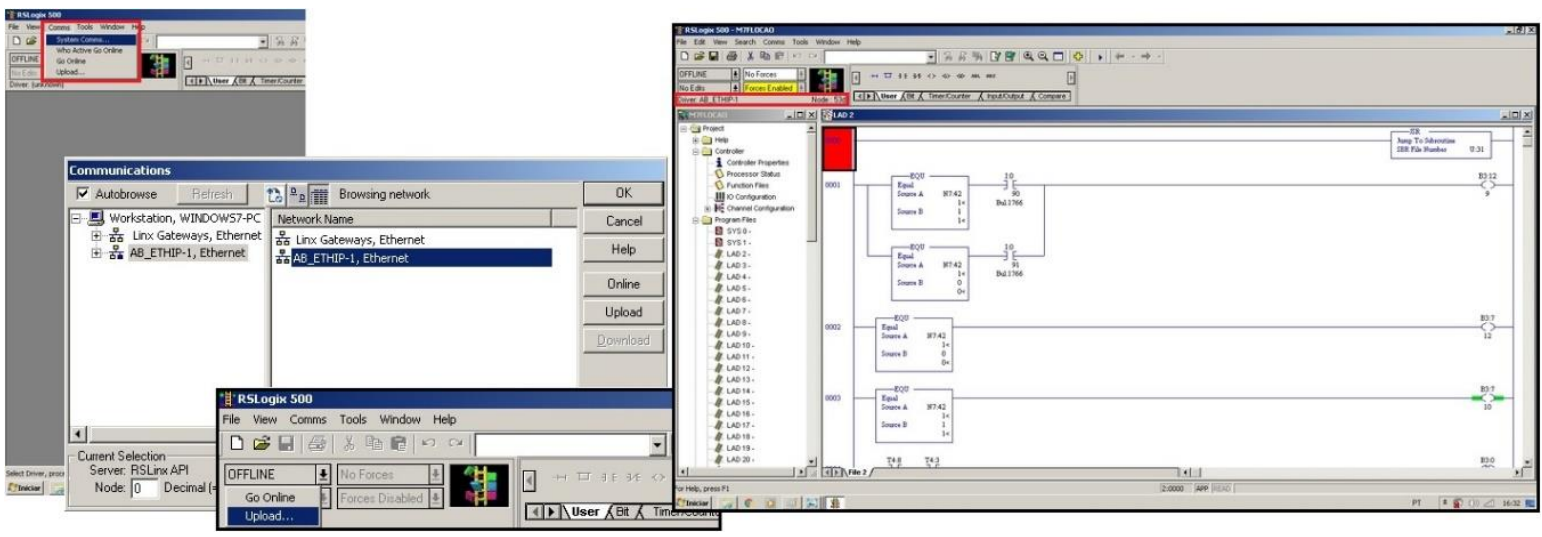

FIGURA 11. Telas RsLogix 500.

Após a comunicação e upload realizado, foi localizado algum trecho do programa onde melhor se adequasse a linha de programa que foi inserida. Sendo assim, como o incremento de programa era relativo a dosagem de produto da máquina, logo, foi localizado o endereço de saída que envia o sinal de solicitação de descarga para a balança, para então a linha ser inserida logo abaixo. Assim sendo, na barra de instruções, foi clicado sobre a função New Rung que realiza a inserção de novas linhas no programa, e assim inserido a linha 39. Ainda na barra de instruções, com a linha 39 selecionada, foi inserido um contato aberto e uma bobina de saída, e depois disso, inserido os endereços. O contato aberto foi endereçado com B3:14/14, conforme havia sido definido no CCW, e a bobina de saída foi endereçada de acordo com a saída disponível, livre e reserva, fisicamente no MicroLogix 1400, que foi O:3/19, que corresponde a saída de número 19 do terceiro slot de expansão de saídas digitais. Finalizado esta etapa, foi realizado o download do programa modificado para o CLP. Seguindo para a barra de status, foi selecionado a opção de Download, e depois disso finalizado o procedimento $[12,13,14,15]$. Toda a descrição desta etapa de incremento no programa, endereçamento e download pode ser acompanhada pelas imagens mostradas na Figura 12.

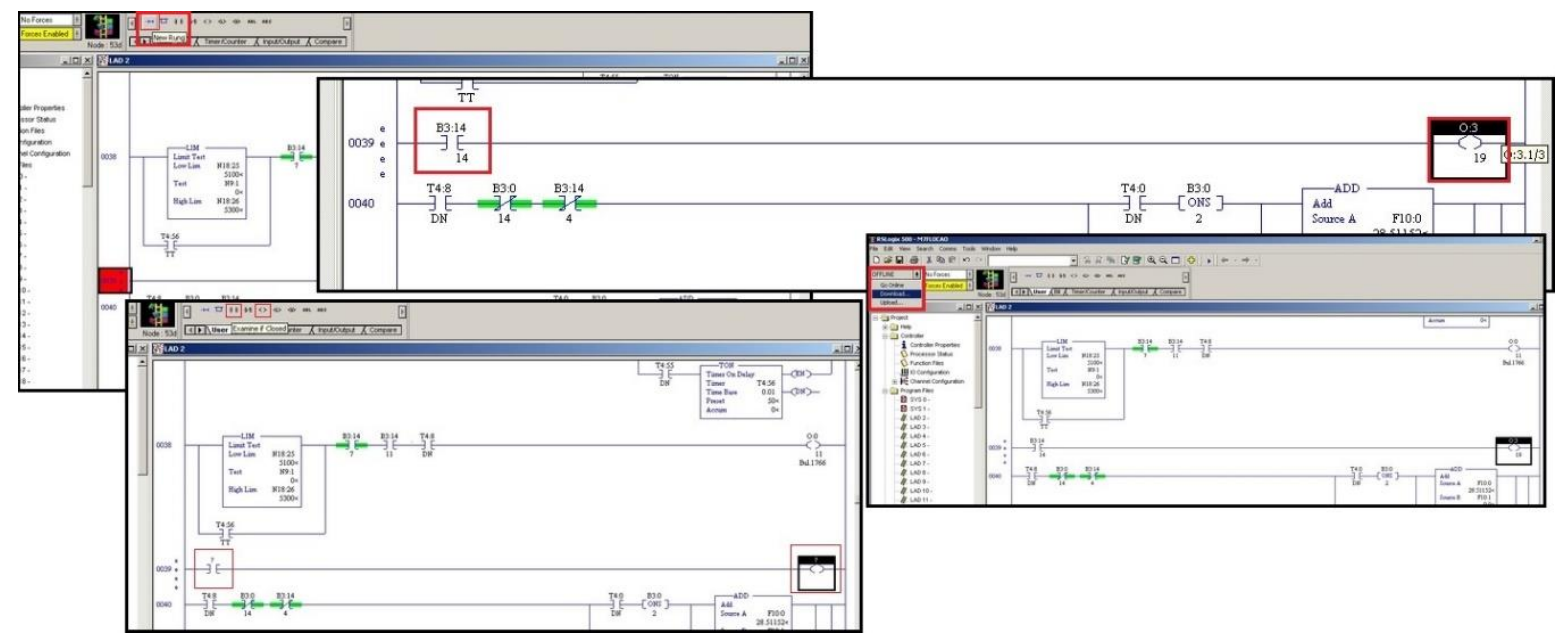

FIGURA 12. Telas incremento programa RsLogix 500. 


\subsubsection{Ligação elétrica dos componentes}

Passado as etapas de desenvolvimento nos softwares, foi feito a ligação elétrica dos componentes. Como a saída do CLP já estava ligada fisicamente ao relé de contato, devido a padronização do fabricante, foi necessário apenas realizar a inserção do contato normalmente aberto do relé em série na linha de acionamento do inversor de frequência do motor da esteira alimentadora, antes controlado apenas pelo contato do relé da balança. $\mathrm{O}$ inversor de frequência, em seus terminais de controle, fornece tensão de 24 Vcc no terminal de número 11 para acionamento de suas próprias entradas digitais $[16,17,18]$. Partindo disto, foi conectado um fio no terminal 11 do inversor, e o mesmo levado ao terminal 11, comum do relé. O terminal 14 do relé, normalmente aberto do relé foi levado ao terminal do relé de controle da balança (Cabeçote dosador) e assim fechado a malha de controle no terminal 1 do inversor, como mostra a Figura 13. Assim, quando acionado o botão de habilitação do alimentador na máquina empacotadora, o mesmo irá mandar um sinal binário em nível alto 1, para o contato aberto endereçado no programa do CLP, que irá fechar e acionar a bobina de saída, fazendo o acionamento do relé e o mesmo fechando o contato e permitindo o acionamento do inversor, nesta ordem de ações, ou vice-versa, se o botão de habilitação do alimentador for desacionado.

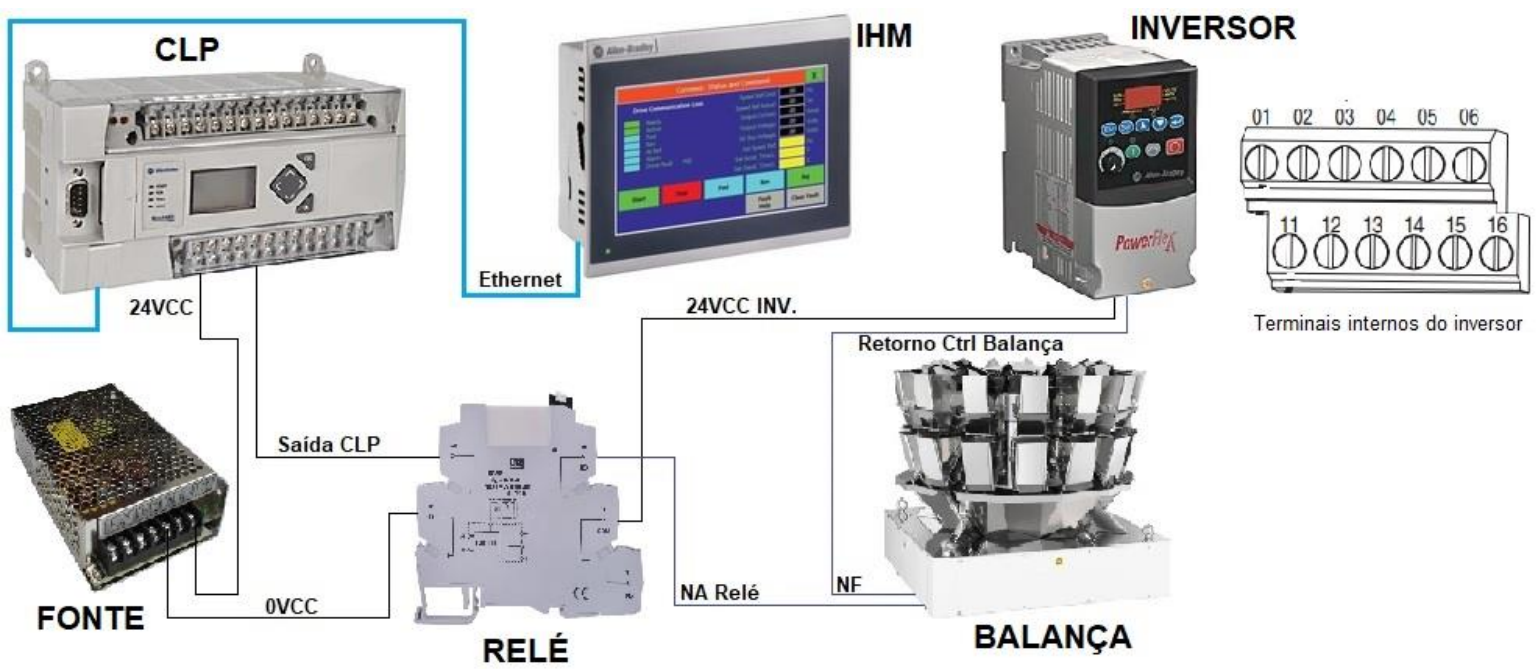

FIGURA 13. Esquema de ligação elétrica de componentes.

\section{RESULTADOS E DisCUSSÃO}

Nas Figuras 14 e 15 são apresentados os resultados alcançados após a implementação em software no processo de controle de alimentação do produto acabado em duas linhas de produção.

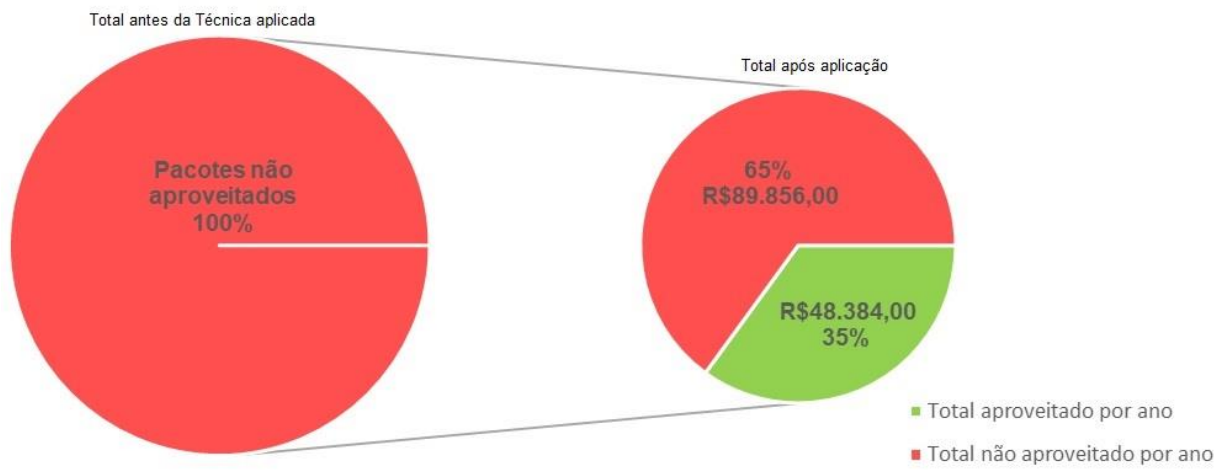

FIGURA 14. Relação de Pacotes aproveitados por melhoria de procedimentos Operacionais. 


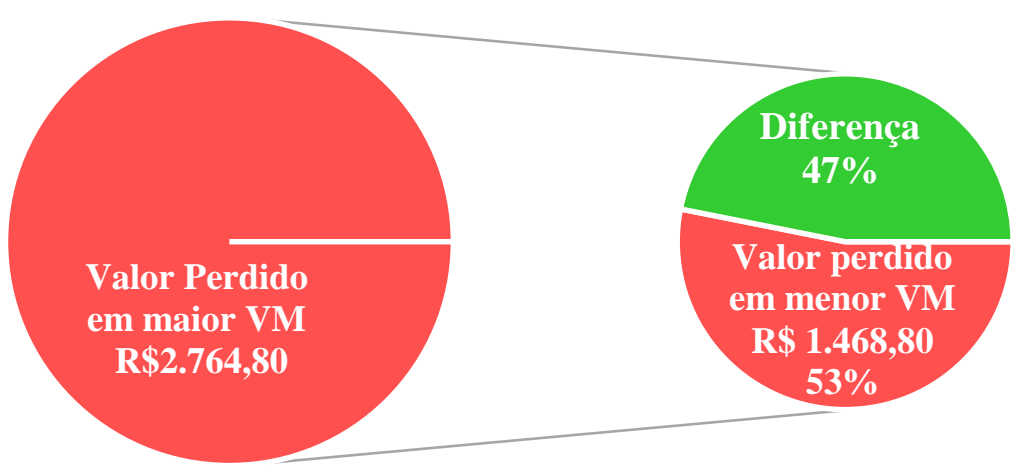

FIGURA 15. Relação de Produtos por Valor de Mercado (VM).

Os efeitos obtidos mostram um aproveitamento que pode atingir a margem de até $35 \%$ da produção que não era aproveitado devido ao procedimento operacional que era praticado antes do proposto pelo trabalho, como mostra a Figura 14. O total de $100 \%$ corresponde a cerca de 200 pacotes que não são produzidos devido as operações padrões de roteiro que são praticadas pela operação no início e decorrer de cada turno de expediente, e definidas pela gestão. O total de $35 \%$ em valor monetário corresponde a um faturamento anual a mais para a empresa de aproximadamente $\mathrm{R} \$ 48.384,00$.

Já o gráfico apresentado pela Figura 15 traduz valores com relação ao aspecto qualitativo. Considerando a possibilidade de a operação não realizar o procedimento operacional de limpeza/ajuste zero da balança, seja este realizado antes da melhoria ou após a mesma, a quantidade de produto desperdiçado que pode não ser reaproveitado pode levar a desvalorização do produto carro-chefe e com maior valor de Mercado da indústria, já que dessa forma, o produto não reaproveitado é destinado para a produção de um outro produto ofertado, porém com menor valor de Mercado, devido a menor qualidade do mesmo. Isto pode ocorrer com maior facilidade se a operação tivesse que realizar sempre o procedimento operacional anterior, pois o mesmo exige mais tempo e pode levar a impaciência do operador para executá-lo. Desta forma, o valor perdido pela indústria pode chegar a $\mathrm{R} \$ 2.764,00$ por ano, considerando a quantidade de produto desperdiçada se fosse comercializado como produto carro-chefe. Esta mesma quantidade de produto, se não reaproveitada com maior qualidade, pode atingir a casa dos 53\% deste valor maior de Mercado. Logo, o produto pode deixar-se de valorizar em cerca de $47 \%$ do seu valor. Ainda neste quesito pode-se destacar a economia de embalagem, que não foi envolvida nos cálculos, porém que também seria desperdiçada em caso de não execução do procedimento. Além disso, vale ressaltar que estes efeitos são apresentados por linha de produção, logo devem ser considerados duplamente.

\section{CONSIDERAÇÕES FINAIS}

Neste trabalho foram apresentadas aplicações de técnicas permitidas através de incrementos nos softwares de comunicação, IHM e CLP por meio do upload de programas de plataforma abertas para aprimoramento no processo de produção, que contemplaram resultados significativos tanto no quesito da otimização de procedimentos experimentais que puderam ser aprimorados, no aspecto quantitativo, quanto na valorização do produto carro-chefe ofertado pela indústria, no que diz respeito ao aspecto qualitativo.

Os resultados obtidos com relação ao aspecto quantitativo, tratam da elevação da produtividade por linha de produção com o aproveitamento em torno de $35 \%$ de pacotes que seriam deixados de serem produzidos devido a um procedimento operacional que foi melhorado. $\mathrm{O}$ aspecto qualitativo dos resultados obtidos mostra a valorização do produto em cerca de $47 \%$ com o não desperdício do produto e o consequente aproveitamento do mesmo com destino para o produto com maior valor de mercado.

Com os resultados apresentados, pode-se afirmar a importância da prática desempenhada por este trabalho, na aplicação de técnicas de programação, dentro da gama da automação industrial, que pode ir desde aplicações de baixa simplicidade, a aplicações mais complexas, porém de grande impacto para o cenário industrial. 


\section{AGRADECIMENTOS}

Os autores agradecem à UFERSA.

\section{REFERÊNCIAS}

[1] Confederação Nacional da Indústria. Produtividade na Indústria. Publicação trimestral da Confederação Nacional da Indústria. Brasília: CNI, 2019. Disponível em: <https://bucket-gw-cni-static-cmssi.s3.amazonaws.com/media/filer_public/0f/da/0fdab904-2167-4717-8a6ea47076692945/produtividade_na_industria_janeiro-marco_2019.pdf >. Acesso em: 05 ago. 2020.

[2] Pasqualini, A M. Fordismo: Uma análise aplicada aos casos do Brasil e Japão. 2004. 67 f. Monografia (Especialização) - Curso de Curso de Graduação em Ciências Econômicas, Universidade Federal de Santa Catarina, Florianópolis, 2004.

[3] Goeking, W. Da máquina a vapor aos softwares de automação. Portal O setor elétrico, Santa Cecília, SP. 2010. Disponível em: https://www.osetoreletrico.com.br/da-maquina-a-vapor-aos-softwares-deautomacao/. Acesso em: 09 out. 2019.

[4] Silveira, L., Lima, W. Q. Um breve histórico conceitual da Automação Industrial e Redes para Automação Industrial. Natal. 2003.

[5] Paiva, L. P. S., Da Silva, E. P., Reis, K. E. G. Estudo de tempos e movimentos: Análise do processo produtivo em uma fábrica de jeans no sudoeste de Minas Gerais. Fortaleza: Abepro, 2015.

[6] Gutierrez, R. M. V. Gutierrez, Pan, S. S. K., dos Reis, M. F. Complexo eletrônico: Automação do controle industrial. In: BNDES. Automação Industrial. Rio de Janeiro: Bndes Setorial, 2008. p. 189-232.

[7] ROCKWELL AUTOMATION, Software de projeto e configuração Connected Components Workbench. Disponível em: <https://www.rockwellautomation.com/pt_BR/detail.page?pagetitle=Software-deprojeto-e-configura\%C3\%A7\%C3\%A3o-Connected-Components-

Workbench\&content_type=tech_data\&docid=c3d2534fe7940da4f474c00dcf8ed7ee>. Acesso em: 09 out. 2019.

[8] Phph.com.br. Software de automação Rockwell RSLinx. Disponível em: <http://www.phph.com.br/firmware-software/clps/item/218-software-de-automacao-rockwellrslinx.html>. Acesso em: 10 out. 2019.

[9] ROCKWELL AUTOMATION; RS Linx ${ }^{\circledR}$ Classic: Obtendo resultados com o guia. 2009. Disponível em: <https://literature.rockwellautomation.com/idc/groups/literature/documents/gr/lnx-gr001_-pt-e.pdf>. Acesso em: 09 out. 2019.

[10] ROCKWELL AUTOMATION, Rslogix $500 . \quad$ Disponível em: <https://www.rockwellautomation.com/rockwellsoftware/products/rslogix500.page>. Acesso em: 09 out. 2019.

[11] Phph.com.br. Software de automação RsLogix 500. Disponível em: <http://www.phph.com.br/firmwaresoftware/clps/item/219-software-de-automacao-rslogix-500.html>. Acesso em: 09 out. 2019.

[12] De Carvalho, D. B. Importância da implantação de Controlador Lógico Programável para a Automação Industrial. 2017. 32 f. TCC (Graduação) - Curso de Engenharia de Controle e Automação, Faculdade Pitágoras de Poços de Caldas, Poços de Caldas, 2017.

[13] Cavalcanti, A. L. O. Controladores lógicos programáveis. Natal, 2011. (Apostila).

[14] Tófili, M. F., Higa, R. A. Estudo comparativo entre CLP e microcontrolador em um elevador de baixa complexidade para carga. Estudo de caso. 2014.

[15] Silveira, C. B. Veja como Funciona o CLP Allen Bradley e Como Programar. Disponível em: <https://www.citisystems.com.br/allen-bradley-clp/>. Acesso em: 11 out. 2019.

[16] De Oliveira, W. R. Uma análise sobre Inversores de frequência e distorções harmônicas e interharmônicas. 2013. 83 f. TCC (Graduação) - Curso de Curso de Graduação em Engenharia de Controle e Automação, Universidade de Brasilia, Brasília, 2013.

[17] Da Silva, L. P. Inversor de frequência. 2011. 42 f. Monografia (Especialização) - Curso de Aperfeiçoamento Para Oficial de Máquinas, Centro de Instrução Almirante Graça Aranha, Rio de Janeiro, 2011.

[18] ROCKWELL AUTOMATION, Inversores PowerFlex 4. Disponível em: <https://ab.rockwellautomation.com/pt/Drives/PowerFlex-4>. Acesso em: 15 out. 2019. 